\title{
Addressing the carbon footprint of health organisations: eight lessons for implementation
}

\section{Kate E Charleswortha,c, Gregory J Stewarta and Peter Sainsburyb}

a Primary Integrated and Community Health, South Eastern Sydney Local Health District, NSW, Australia

b School of Public Health, University of Sydney, NSW, Australia

c Corresponding author: kate.charlesworth@health.nsw.gov.au

\section{Article history}

Publication date: December 2018

Citation: Charlesworth KE, Stewart GJ, Sainsbury P. Addressing the carbon footprint of health organisations: eight lessons for implementation. Public Health Res Pract. 2018;28(4):e2841830. https://doi. org/10.17061/phrp2841830

\section{Key points}

- Health organisations are large carbon polluters and must reduce their emissions

- Some health organisations in New South Wales, Australia, have environmental sustainability plans but efforts to reduce carbon emissions have been largely ineffective

- We offer eight lessons about how to operationalise environmental sustainability initiatives in health organisations

\section{Abstract}

Background: The scientific evidence for global warming is overwhelming. Health organisations, as large carbon polluters, are at significant 'carbon risk' and must act to reduce their carbon emissions. Many environmental sustainability initiatives, if properly implemented, would not only reduce harm, waste and pollution but also deliver health, social and financial benefits.

Method: We have been involved for more than a decade in efforts to reduce the greenhouse gas emissions of New South Wales (NSW) Health organisations in which we have worked. We draw on our collective experience to offer eight key lessons about implementing environmental sustainability initiatives in health organisations.

Results: Sustainability plans have been developed in at least three Area Health Services/Local Health Districts in NSW, but in each case they have been imperfectly implemented.

Lessons learnt: Based on our experience, we offer eight key lessons relating to leadership, engagement and developing networks, data, complex adaptive systems, broadening the issue, and political factors. 


\section{Introduction}

The science of global warming is beyond dispute and beyond denial. ${ }^{1}$ In 2011, Christopher Rapley (Professor of Climate Science, University College London, and former Director of the British Antarctic Survey) summarised the science using four critical questions:

- Is the planet warming?

- Is it us?

- Does it matter?

- Must we do something?

To all four questions Professor Rapley's answer was "yes". ${ }^{2}$ A concerted response to the fourth question is now more urgent than ever.

It is beyond dispute that modern, complex health systems are large emitters of greenhouse gases and that health systems have a responsibility to respond to global warming by reducing their own emissions. In the UK, the National Health Service (NHS) has been remarkably successful in reducing carbon emissions by $11 \%$ during the past decade, despite activity increasing by $18 \%{ }^{3}$ The US has also measured the carbon footprint of its health system ${ }^{4}$ and a number of healthcare organisations are acting to improve their environmental performance. ${ }^{5}$ In Australia, the health sector produces $7 \%$ of total national carbon emissions. Hospitals (including their capital expenditure) comprise about half of the footprint, and pharmaceuticals nearly $20 \% .{ }^{6}$ Several state governments, including NSW, have set the twin targets of 'net zero' carbon emissions by 2050 and making the state more resilient to a changing climate. ' 'Carbon risk' in relation to health organisations has two aspects. First, extreme weather events (which are becoming more common and more severe as global warming increases) may damage health facilities and reduce operational capacity. Second, health services are large carbon polluters and it is likely that they will soon be formally required to demonstrate that they are measuring, monitoring and reducing greenhouse gas emissions. The good news is that, once implemented, many initiatives to reduce carbon risk will concurrently deliver health, social and financial benefits. ${ }^{3}$

We have been actively engaged for more than a decade in efforts to understand, plan for and reduce carbon pollution in the organisations in which we have worked. The first author gained additional expertise in environmentally sustainable healthcare while working at the NHS Sustainable Development Unit (SDU) in the UK and through doctoral research on environmentally sustainable health systems..$^{8,9}$ In November 2017, South Eastern Sydney Local Health District (SESLHD), South Western Sydney Local Health District (SWSLHD) and the University of Sydney cohosted a NSW Planetary Health and Sustainable Healthcare Forum to engage with staff across NSW Health and to assess progress on environmental sustainability in NSW. Our candid assessment is that progress has been made, particularly with small-scale initiatives around energy efficiency, recycling and active travel. Further, there is a growing understanding among health professionals 1) that climate change is not only an environmental issue but also a health issue; 2) of the environmental impacts of health systems (the carbon footprint, water use, generation of vast amounts of waste, plastic pollution, etc.); and 3) of the opportunities and responsibilities we have to protect and promote human health by improving our environmental sustainability performance. However, much more needs to be done. In this article we draw on our own observations and experiences, as well as outcomes from the Forum, to describe eight lessons for promoting environmental sustainability in health services.

\section{Eight lessons for implementing environmental sustainability} initiatives

\section{Lesson 1: Plans are necessary, but implementation is more important}

We have been involved with the development of environmental sustainability strategies and plans in three separate Area Health Services and Local Health Districts (LHDs). The common key action areas, which go beyond just carbon emissions, were:

- Governance

- Organisational leadership

- Energy

- Water

- Transport

- Food

- Waste

- Pharmaceuticals

- Procurement

- Capital works

- Office practices

- Clinical practices

- Benchmarking, monitoring and evaluation.

Although staff have generally been enthusiastic, and there has been some progress, the plans have not been sufficiently operationalised, particularly in relation to reducing carbon emissions. A progress report at the halfway point of the SESLHD's Sustainability Plan (November 2015) demonstrated that, although there had been progress in some areas (e.g. energy efficiency, reduced pharmaceutical packaging, active travel, sustainable office practices, reducing clinical waste through waste segregation), overall there had been slow progress in implementing the plan (SESLHD internal document). This demonstrates that, although a plan is necessary, it is not itself the primary driver of change; it is merely an enabler. Other factors (including the seven lessons below) are necessary for effectively operationalising initiatives in a health service. 
As a preliminary comment, we note that approaches to improving quality in healthcare in recent years have adopted the concept of healthcare as a 'complex adaptive system'10,11 where change occurs not through top-down hierarchical structures, but through selforganising and adaptive networks of agents with a collective purpose. We view this approach as more promising than past approaches for achieving progress towards health system environmental sustainability.

\section{Lesson 2: Leadership is vital - at all levels}

Leadership is required at many levels - state, district, clinical, academic and personal - from the organisational head to the most junior staff member. In our experience mid-ranking managers and junior nursing and medical staff are often the most innovative and engaged drivers of sustainability initiatives.

At the Planetary Health and Sustainable Healthcare Forum one frequently identified barrier was a lack of national or state leadership on this issue and the absence of any state-wide sustainability framework. NSW Health has a Resource Efficiency Strategy for 2016-2023 $3^{12}$ but this only covers energy, water and waste management, not the broader sustainability issues around comprehensive carbon metrics, innovative models of care and optimising use of new technologies. To advance this agenda, the NSW Office of Environment and Heritage and NSW Health have recently funded a Climate Change, Human Health and Social Impacts Research Node at the University of Sydney (sydney.edu.au/medicine/publichealth/research/hhsi-node.php).

\section{Lesson 3: Involve everyone but identify resources to support implementation}

One discovery at the Forum was that sustainability initiatives are frequently being undertaken by passionate and committed clinical and nonclinical staff and managers without any formal resources or support. For example, in SESLHD the sustainability plan was developed by a temporary public health trainee. No ongoing resources were available for a sustainability manager to support staff to implement the plan. Some LHDs and hospitals now employ sustainability managers, and we strongly recommend that every LHD employ one and that they be supported by a Sustainability Unit within the NSW Ministry of Health. One of the important tasks of an LHD sustainability manager is to identify, mobilise and establish networks of supporters at all levels of the organisation - from front-line staff to the executive and board. Our observation is that there are many potential supporters within the health system but that the right 'triggers' (motivations, which are different for everyone) to engage them must be found. LHDs should also consider joining the Global Green and Healthy Hospitals network for access to resources and international networks (www.greenhospitals.net).

\section{Lesson 4: Good data are a good start}

In our experience, and consistent with feedback at the Forum, comprehensive data and data collection systems are necessary for measuring baseline carbon footprints, identifying sources of emissions (to identify 'carbon hotspots'), monitoring progress and evaluating carbon reduction initiatives. Data are needed to make the case for action, engage staff, ensure accountability and recognise improvement. A decade ago, the NHS SDU began measuring the NHS's carbon footprint and has demonstrated that its $11 \%$ carbon emissions reduction also saved $£ 1.85$ billion. ${ }^{13,14}$

In NSW we are only just beginning to measure greenhouse gas emissions. In 2016-17, SESLHD commissioned a Greenhouse Gas Emissions Assessment for 2011-12 to 2014-15, to be extended to 2016-17. There are three components (scopes) in a carbon footprint assessment: scope 1 is direct, on-site emissions caused by fuel combustion (gasoline, diesel and natural gas); scope 2 is emissions from purchased electricity; and scope 3 is supply chain emissions associated with capital and operational expenditure (the manufacture and delivery of goods). At SESLHD the total emissions (185 kilotonnes of carbon dioxide equivalent) were dominated by scope 2 (41\%) and scope 3 emissions (47\%). ${ }^{15}$ High contributors to the scope 3 emissions were food, pharmaceuticals, and surgical and medical products. ${ }^{15}$ This information will guide sustainability initiatives in SESLHD.

\section{Lesson 5: Environmental sustainability is much broader than 'green' initiatives}

A key finding from the NHS and Australia is that models of care and the products used are major contributors to the carbon footprint.6,13 Our current system of healthcare - heavily oriented around hospital care, pharmaceuticals, and medical devices and interventions - is fundamentally carbon and resource intensive. Therefore, although 'green' initiatives such as energy efficiency and staff travel plans are important, the broader challenges are about transformational changes to our models and systems of care.

Accordingly, the great challenge is to engage clinicians in changing practice and developing new models of care. Although it is not yet apparent what an environmentally sustainable system of care might look like, research indicates that the following are important:

- Greater emphasis on community and primary care (with telephone and email conversations, group visits, care teams and patient self-management education) and prevention of the preventable, with a focus on health behaviour and lifestyle changes

- Developing innovative and more integrated models of care

- Optimising information communication technology, frequently as an enabler of new models of care 
- Focus on 'value'; this entails reducing 'low value' care (where the harms, risks, and carbon and financial costs of an investigation, treatment or prescription exceed any potential benefit) and using new (and low-carbon) sources of value such as people and relationships (e.g. patient empowerment, social prescribing, peer-to-peer models, broader definition of health workers). ${ }^{8,9,16}$

This range of factors bears a striking resemblance to the developing notion of better 'integrated care' being a lever for population health approaches and wholeof-system change. ${ }^{17} \mathrm{NSW}$ Health will soon publish a strategic framework for better integrated care in NSW.

\section{Lesson 6: Facilitate effective engagement}

In our experience, although outright opposition to environmental sustainability initiatives from staff is rare, more often there is resistance from professional groups who feel that such initiatives are contrary to, or in competition with, their professional objectives. For example, in one health service the sustainability committee suggested that a 'meat-free Monday' would improve health, reduce carbon emissions and be symbolically important. This was opposed by nutritionists who viewed daily meat on hospital menus as essential to correct malnutrition in some patients, a critical issue for them. We have also encountered 'passive inactivity', such as difficulties in gaining access to relevant energy, waste, water and procurement data that are tightly held by finance staff. Another related and common concern is that sustainability initiatives will overburden staff. The executive of one health service, although supportive of action on climate change, was concerned that a comprehensive plan containing detailed sustainability targets would add too much to hospital general managers' performance requirements.

To address these concerns, we need to emphasise that environmentally sustainable actions are aligned with the other objectives of the health organisation: providing quality healthcare, improving patient experience, greater efficiency, consistency and relevance, and financial sustainability. That is, environmental sustainability can be rightly positioned as one dimension of quality healthcare.

\section{Lesson 7: Build a network}

Our observation is that there are some pockets of promising practice throughout the system. These are in areas of energy, waste and travel, and also new models of care around social prescribing, peer-to-peer models, building social value, telehealth and telecare. However, there is little opportunity or capacity for interested staff to be engaged in coordinated carbon reduction activities. Effective networks (geographical, professional and for specific issues) need to be developed within LHDs and across NSW Health and partner organisations. The Forum was an effort towards developing such a network. It will need to be followed up and nurtured.

\section{Lesson 8: Encourage political awareness}

Climate change, in Australia and elsewhere, is an intensely political and party-political issue. Because of this, effective government action does not occur simply because of good evidence and rational policy making. Similarly, change does not come about in health services simply based on the evidence. Staff members, members of executives and boards will nearly all have (often strong) views about the existence of climate change, what is causing it, whether anything needs to be done about it and whether tackling climate change is core business for health services, whose main task is often seen to be to treat (not even prevent) illness and injury. Anyone wanting to create a more sustainable health system must work with this reality and not just complain about people ignoring the evidence and/or being consumed by their own narrow interests.

Encouragingly, in the absence of national leadership, some state and local governments, and sections of the private and public sectors, are moving ahead on climate action. ${ }^{18,19}$ Therefore, 'Think globally, act locally' and its corollary 'Think locally, act locally ... now' are powerful motivators for overcoming political barriers. Indeed, these sentiments should continue to motivate all of us in responding to what the Lancet Commission reports have rightfully described as both the greatest health threat and greatest health opportunity of the 21 st century. ${ }^{20}$

\section{Acknowledgements}

We thank Ricardo Schwanz for his summary of the NSW Planetary Health and Sustainable Healthcare Forum.

\section{Peer review and provenance}

Externally peer reviewed, commissioned.

\section{Competing interests}

$\mathrm{KC}$ is a member of the Climate and Health Alliance. KC and GS are members of Doctors for the Environment, Australia. PS is president of the Climate and Health Alliance.

\section{Author contributions}

$\mathrm{KC}, \mathrm{GS}$ and PS were jointly responsible for designing the manuscript. KC drafted and edited the manuscript. GS and PS critically reviewed and edited the manuscript. All authors approved the final version of the manuscript. 


\section{References}

1. McCoy D, Montgomery H, Arulkumaran S, Godlee F. Climate change and human survival. BMJ. 2014;348:g2351.

2. Godlee F. How on earth do we combat climate change? BMJ. 2011;343:d6789.

3. Pencheon D. Developing a sustainable health care system: the United Kingdom experience. MJA. 2018;208(7):284-5.

4. Chung JW, Meltzer DO. Estimate of the carbon footprint of the US health care sector. JAMA. 2009;302:1970-2.

5. Kaiser Permanente. Oakland, CA: Oakland, California; 2013-2018. Environmental stewardship [about 2 screens]; [cited 2018 Oct 11]. Available from: share. kaiserpermanente.org/community-health/environmentalstewardship/

6. Malik A, Lenzen M, McAlister S, McGain F. The carbon footprint of Australian health care. Lancet Planetary Health. 2018;2:e27-35.

7. Office of Environment and Heritage. NSW Climate Change Policy Framework. Sydney: State of NSW and Office of Environment and Heritage; 2016 [cited 2018 Oct 11]. Available from: www.environment.nsw.gov.au/-/ media/OEH/Corporate-Site/Documents/Climate-change/ nsw-climate-change-policy-framework-160618.pdf

8. Charlesworth KE, Jamieson M. New sources of value for health and care in a carbon-constrained world. J Public Health (Oxf). 2017;39(4):691-7.

9. Charlesworth KE, Jamieson M. Healthcare in a carbonconstrained world. Aust Health Rev. 2018 [Epub ahead of print].

10. Institute for Healthcare Improvement. $10 \mathrm{IHI}$ innovations to improve health and health care. Cambridge, MA: IHI; 2017 [cited 2018 Oct 11]. Available from: www.ihi.org/ resources/Pages/Publications/10-IHI-Innovations-toImprove-Health-and-Health-Care.aspx

11. Lipsitz LA. Understanding health care as a complex system. JAMA. 2012;308(3):243-4.

12. NSW Health. Resource efficiency strategy 2016 to 2023. Sydney: NSW Health; 2016 [cited 2018 Oct 11]. Available from: www.health.nsw.gov.au/assets/Publications/ resource-efficiency-strategy.pdf
13. NHS England, Public Health England. Sustainable development in the health and care system: health check 2016. Cambridge, UK: Sustainable Development Unit; 2016 [cited 2018 Oct 11]. Available from: www.sduhealth. org.uk/documents/publications/2016/20160119\%20 SDUupdate2016\%20Web.pdf

14. Baddley J. Sustainable development in health: health check 2017 report. Cambridge, UK: Sustainable Development Unit; 2016 [cited 2018 Oct 11]. Available from: www.sduhealth.org.uk/documents/resources/ Presentations/SDU_event_feb2017_JBaddley_ Healthcheck2017.pdf

15. Dey C. A greenhouse gas emissions assessment for SESLHD for the four financial years 2011-12 to 2014-15 Sydney: South Eastern Sydney Local Health District; 2017.

16. Tomson $\mathrm{C}$. Reducing the carbon footprint of hospitalbased care. Future Hospital Journal. 2015;2:57-62.

17. Alderwick H, Ham C, Buck D. Population health systems: going beyond integrated care. London: The King's Fund; 2015 [cited 2018 Oct 11]. Available from: www.kingsfund. org.uk/sites/default/files/field/field_publication_file/ population-health-systems-kingsfund-feb15.pdf

18. Horsburgh N, Armstrong F, Mulvenna V. Framework for a national strategy on climate, health and wellbeing for Australia. Melbourne: Climate and Health Alliance; 2017 [cited 2018 Oct 11]. Available from: www.aph.gov.au/ DocumentStore. ashx?id=646904fe-2186-46f0-b7845 c40307576c3\&subld=514102

19. Victoria State Government. Climate Change Act 2017. Melbourne: State Government of Victoria; 2017 [cited 2018 Aug 12]. Available from: www.climatechange.vic. gov.au/legislation/climate-change-act-2017

20. Wang $\mathrm{H}$, Horton R. Tackling climate change: the greatest opportunity for global health. Lancet. 2015;386(10006):1798-9.

\section{Copyright: (c) (i) (2)}

(C) 2018 Charlesworth et al. This article is licensed under the Creative Commons Attribution-NonCommercial-ShareAlike 4.0 International Licence, which allows others to redistribute, adapt and share this work non-commercially provided they attribute the work and any adapted version of it is distributed under the same Creative Commons licence terms. See: www.creativecommons.org/licenses/by-nc-sa/4.0/ 